\title{
Abrasion of Candidate Spacesuit Fabrics by Simulated Lunar Dust
}

James R. Gaier and Mary Ann Meador Glenn Research Center, Cleveland, Ohio

Kerry J. Rogers

Manchester College, North Manchester, Indiana

Brennan H. Sheehy

Oregon Institute of Technology, Klamath Falls, Oregon 


\section{NASA STI Program . . . in Profile}

Since its founding, NASA has been dedicated to the advancement of aeronautics and space science. The NASA Scientific and Technical Information (STI) program plays a key part in helping NASA maintain this important role.

The NASA STI Program operates under the auspices of the Agency Chief Information Officer. It collects, organizes, provides for archiving, and disseminates NASA's STI. The NASA STI program provides access to the NASA Aeronautics and Space Database and its public interface, the NASA Technical Reports Server, thus providing one of the largest collections of aeronautical and space science STI in the world. Results are published in both non-NASA channels and by NASA in the NASA STI Report Series, which includes the following report types:

- TECHNICAL PUBLICATION. Reports of completed research or a major significant phase of research that present the results of NASA programs and include extensive data or theoretical analysis. Includes compilations of significant scientific and technical data and information deemed to be of continuing reference value. NASA counterpart of peer-reviewed formal professional papers but has less stringent limitations on manuscript length and extent of graphic presentations.

- TECHNICAL MEMORANDUM. Scientific and technical findings that are preliminary or of specialized interest, e.g., quick release reports, working papers, and bibliographies that contain minimal annotation. Does not contain extensive analysis.

- CONTRACTOR REPORT. Scientific and technical findings by NASA-sponsored contractors and grantees.
- CONFERENCE PUBLICATION. Collected papers from scientific and technical conferences, symposia, seminars, or other meetings sponsored or cosponsored by NASA.

- SPECIAL PUBLICATION. Scientific, technical, or historical information from NASA programs, projects, and missions, often concerned with subjects having substantial public interest.

- TECHNICAL TRANSLATION. Englishlanguage translations of foreign scientific and technical material pertinent to NASA's mission.

Specialized services also include creating custom thesauri, building customized databases, organizing and publishing research results.

For more information about the NASA STI program, see the following:

- Access the NASA STI program home page at http://www.sti.nasa.gov

- E-mail your question via the Internet to help@ sti.nasa.gov

- Fax your question to the NASA STI Help Desk at $443-757-5803$

- Telephone the NASA STI Help Desk at 443-757-5802

- Write to: NASA Center for AeroSpace Information (CASI) 7115 Standard Drive Hanover, MD 21076-1320 


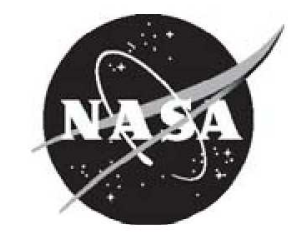

\section{Abrasion of Candidate Spacesuit Fabrics by Simulated Lunar Dust}

James R. Gaier and Mary Ann Meador

Glenn Research Center, Cleveland, Ohio

Kerry J. Rogers

Manchester College, North Manchester, Indiana

Brennan H. Sheehy

Oregon Institute of Technology, Klamath Falls, Oregon

Prepared for the

39th International Conference on Environmental Systems (ICES)

sponsored by the Society of Automotive Engineers International

Savannah, Georgia, July 12-16, 2009

National Aeronautics and

Space Administration

Glenn Research Center

Cleveland, Ohio 44135 


\section{Acknowledgments}

Small samples from the Apollo 12 suit worn by Alan Bean on the lunar surface and samples of the Apollo-era plain weave FEP were kindly supplied by J.J. Kosmo (NASA Johnson Space Center). J.S. Ware (ILC Dover, L.L.C.) kindly provided the rest of the samples. Funding and programmatic support were supplied by the Dust Mitigation Project of NASA Exploration Technology Development Program. K.J.R. and B.H.S. were supported by the Lewis Educational Research and Collaborative Internship Program of the NASA Glenn Research Center.

Trade names and trademarks are used in this report for identification only. Their usage does not constitute an official endorsement, either expressed or implied, by the National Aeronautics and Space Administration.

Level of Review: This material has been technically reviewed by technical management.

Available from

NASA Center for Aerospace Information 7115 Standard Drive

Hanover, MD 21076-1320
National Technical Information Service 5285 Port Royal Road Springfield, VA 22161

Available electronically at http://gltrs.grc.nasa.gov 


\title{
Abrasion of Candidate Spacesuit Fabrics by Simulated Lunar Dust
}

\author{
James R. Gaier and Mary Ann Meador \\ National Aeronautics and Space Administration \\ Glenn Research Center \\ Cleveland, Ohio 44135 \\ Kerry J. Rogers \\ Manchester College \\ North Manchester, Indiana 46962 \\ Brennan H. Sheehy \\ Oregon Institute of Technology \\ Klamath Falls, Oregon 97601
}

\begin{abstract}
A protocol has been developed that produced the type of lunar soil abrasion damage observed on Apollo spacesuits. This protocol was then applied to four materials (Kevlar (DuPont), Vectran (Kuraray Co., Ltd.), Orthofabric, and Tyvek (DuPont)) that are candidates for advanced spacesuits. Three of the four new candidate fabrics (all but Vectran) were effective at keeping the dust from penetrating to layers beneath. In the cases of Kevlar and Orthofabric this was accomplished by the addition of a silicone layer. In the case of Tyvek, the paper structure was dense enough to block dust transport. The least abrasive damage was suffered by the Tyvek. This was thought to be due in large part to its nonwoven paper structure. The woven structures were all abraded where the top of the weave was struck by the abrasive. Of these, the Orthofabric suffered the least wear, with both Vectran and Kevlar suffering considerably more extensive filament breakage.
\end{abstract}

\section{Introduction}

One of the challenges facing the next generation of Moon landings is to make extravehicular activity (EVA) suits that will stand up to months of use on the lunar surface. Although the Apollo Extravehicular Mobility Units (EMUs) performed nearly flawlessly, they were used no more than three times over a period that did not exceed $75 \mathrm{hr}$. The EMU Pressure Garment Assemblies (PGAs), commonly called "spacesuits", sustained much more damage due to abrasion during lunar surface operations than expected. For example, it was reported that during Apollo 12 the suit material just beneath the tops of the lunar boots chafed sufficiently to wear through the outer thermal control layer, the $\beta$-cloth micrometeoroid protective layer in several spots, and was beginning to wear through the Mylar multilayer insulation beneath (Ref. 1). Figure 1 shows a photograph of a similar problem in an Apollo 17 suit. They also reported that the wear on the suits after just $8 \mathrm{hr}$ on the lunar surface was greater than that of their training suits after more than a hundred hours of use (Ref. 2). Since current plans call for suits that will probably be required to last hundreds of

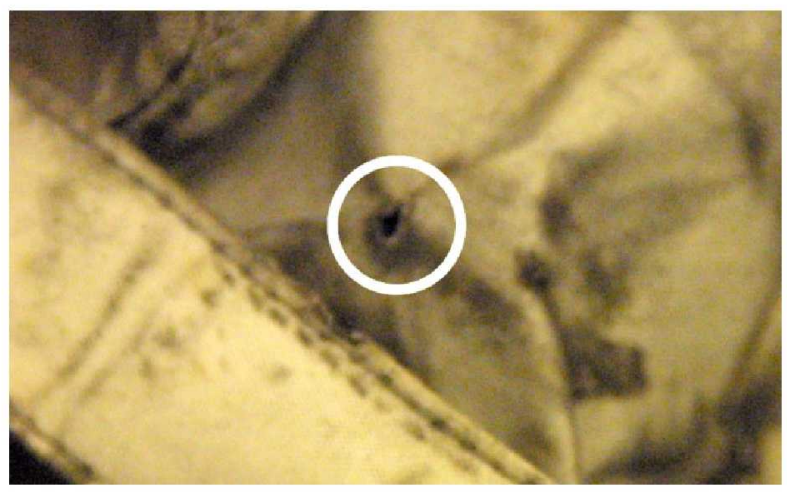

Figure 1.-A portion of the leg of Harrison Schmitt's Apollo 17 pressure garment assembly showing a hole worn through the outer layer above the boot.

call for suits that will probably be required to last hundreds of EVA hours on the lunar surface, it seems clear that the abrasion resistance of the fabrics used for the suits during the Apollo program will need to be improved upon.

There have been many advances in suit fabrics since the $f$ call for suits that will probably be required to last hundreds of EVA hours on the lunar surface, it seems clear that the abrasion resistance of the fabrics used for the suits during the Apollo program will need to be improved upon.

There have been many advances in suit fabrics since the fluorinated ethylene propylene (FEP) fabric outer layer of the Apollo program. But none of these materials has been subjected to the rigors of working on the lunar surface. So there is great interest in doing comparative studies that would quantify how well the new materials hold up in the lunar environment. Kosmo et al., at the NASA Johnson Space Center (JSC) found that lunar simulant ground into FEP fabric with a mortar and pestle showed abrasion features similar to those observed on the Apollo suits (Ref. 3). Part of the impetus for this study was to reproduce those results in a more controlled way. To this end, a protocol was developed based on a standard ASTM test to try to produce the abrasion seen on the Apollo FEP fabric. Once the protocol was developed, candidate suit materials were subjected to the same conditions to evaluate their relative abrasion resistance. 


\section{Methods and Materials}

Seven different PGA outer fabric materials were tested in this study. Two were FEP fabrics that were fabricated during the Apollo era and used on the original suits. Most of the Apollo suits were made of a plain weave FEP, but some of the suits used a twill weave FEP instead. This included the Apollo 12 suit worn by Alan Bean. The trouser section of this suit is the only portion of the original Apollo suits that was used for destructive testing, and a small piece of it was obtained. Spacesuits used in the Shuttle Program and on the International Space Station have an Orthofabric outer layer, so this was a third candidate. Tyvek has been proposed as a material to make disposable coveralls to cover the PGA during EVAs on the lunar surface to minimize the amount of dust transferred onto the suits, and so it was tested. Three siliconebacked fabrics are being considered for advanced spacesuits as well, Orthofabric, Kevlar, and Vectran and so these were also tested. Table I summarizes the types of fabric tested.
There were three suites of tests run on these fabrics, and the last three columns of Table I indicate which fabrics were used for the tests. The first two experiment suites were run in the Lunar Dust Adhesion Bell Jar (LDAB) (Ref. 4). These tests utilized abrasion wheels made of polytetrafluoroethylene (PTFE). The second suite of tests, considered several types of abrasion wheels and concluded that the S-39 wheel (Taber Industries), which is a leather-covered brass wheel gave the best results. The third suite of experiments, which was carried out in atmosphere using the S-39 wheels, investigated the effects of abrasion wheel pressure on the abrasion of fabrics and found that lower pressure resulted in more realistic damage. Results for the PTFE abrasion wheels and the S-39 wheels operated at low wheel pressure will be the focus of this report. Results of the second suite of tests are not reported as those results were similar to the first. Similarly, there were no appreciable differences between the abrasion results of the plain weave and twill weave FEP, so only the twill weave results are reported.

TABLE I.-FABRICS EVALUATED IN ABRASION TESTS

\begin{tabular}{|l|l|c|c|c|}
\hline \multicolumn{1}{|c|}{ Fabric Material } & \multicolumn{1}{|c|}{ Significance } & PTFE & S-39 & Low P \\
\hline Plain weave FEP & Used on most Apollo suits & $\checkmark$ & & \\
\hline Twill weave FEP & Used on Alan Bean's Apollo 12 suit & $\checkmark$ & $\checkmark$ & \\
\hline Orthofabric & EVA suits for Shuttle and ISS & $\checkmark$ & $\checkmark$ & \\
\hline Tyvek & Candidate material for disposable covers & $\checkmark$ & $\checkmark$ & $\checkmark$ \\
\hline Silicone coated Orthofabric & Candidate material & & & $\checkmark$ \\
\hline Silicone coated Kevlar & Candidate material & & & $\checkmark$ \\
\hline Silicone coated Vectran & Candidate material & & $\checkmark$ \\
\hline
\end{tabular}

\section{Abrasion Protocol}

A protocol was developed that was based on ASTM D 3884-01, "Standard Guide for Abrasion Resistance of Textile Fabrics (Rotary Platform, Double Head Method)." In this method a fabric is "abraded using a rotational rubbing action under controlled conditions of pressure and abrasive action." A test fabric is mounted onto a horizontally mounted rotating disk. Two free-wheeling abrasion wheels are mounted vertically and ride on top of the fabric on either side of its rotation axis. But the centerline between the abrasion wheels is offset from the axis of the sample disk causing one to rub against the specimen outward towards the edge of sample disk, and the other rubs against the specimen inward toward the center of the sample disk (Fig. 2). The resulting abrasion pattern forms a pattern of crossed arcs.

The test fabric sample was securely mounted onto a $15 \mathrm{~cm}$ $(6.0$ in.) diameter aluminum disk covered with a PTFE sheet. The PTFE sheet served to keep the dust from abrading the aluminum plate below the fabric and thus complicating the analysis. The fabric must not stretch and wrinkle during the test. In order to conserve precious specialty fabric, and to facilitate mounting the fabric tightly over the sample disk, four 9 by $15 \mathrm{~cm}$ fabric samples were mounted at once in an overlapping pattern such that each covered half of the sample disk, half on top of one adjacent fabric, and half below the other adjacent fabric. The inner edges were sandwiched below a washer, and the outer below a mounting ring. It was important for the samples to be held very tightly as any small wrinkles were immediately pulled up by the abrasion wheels. Early trials utilized several candidate fabrics at once, but for the final data, only one quadrant contained the test sample and the rest were a commercial cotton fabric.

Since the abrasion by loose dust was desired, standard abrasion wheels were not used. In the first series of tests

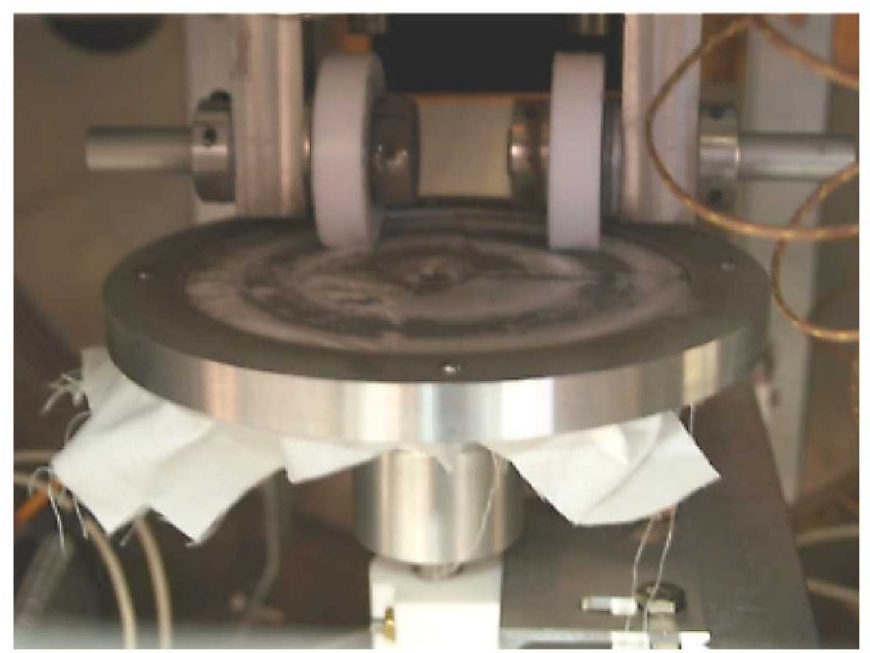

Figure 2.-A photograph showing the abrasion test setup for the fabric samples. 
wheels made of PTFE were used, with the thought of not adding the complicating factor of an additional material. In order to try to reproduce the surface chemistry of the lunar regolith on the simulant particles, these tests were run in the lunar dust adhesion bell jar (LDAB), a facility that provides a high fidelity lunar simulation environment (Ref. 6). At this time it is not known how significant the surface chemistry is to the regolith's abrasive properties. The abradant grit used was JSC-1A lunar stimulant (Ref. 6). This material is similar in bulk chemistry and glass content to the soil found on the mare regions of the Moon, and at the time of the study was the de facto lunar simulant being used in most NASA studies. These tests were carried out in a vacuum of about $10^{-4} \mathrm{~Pa}\left(10^{-6}\right.$ torr) using lunar simulant that had been activated first by oxidation in a radio frequency plasma, then heated to $200^{\circ} \mathrm{C}$ overnight, then reduced in a hydrogen-helium plasma to simulate the effects of solar wind exposure. It was then dumped onto the fabric in vacuo, and spread with a soft brush. The fabric was rotated against the abrasion wheels at $70 \mathrm{rpm}$ for a specified number of revolutions, usually 8000 cycles.

But, as shown below, the PTFE wheels tended to squeeze the dust out of the way and simply smear out the soft coating of the fibers. After several other abrasive wheel materials were tried, Taber Industries type S-39 wheels were chosen. These have a leather strip mounted to a brass hub, and are recommended by the manufacturer for loose grit tests. The dust caught in the leather wheels and scraped across the samples without apparent contamination by the leather. The third series of tests was carried out on the bench top due to the unavailability of the LDAB.

A layer of lunar simulant with particles size $<100 \mu \mathrm{m}$ was applied with a soft brush to the entire exposed surface of the fabric. The dusted sample wheel was then mounted on the test apparatus in a fume hood, and the leather abrasion wheels, suitably counterweighted by an empirically determined amount, were lowered onto the surface. As before, the fabric was rotated against the abrasion wheels at $70 \mathrm{rpm}$ for a specified number of revolutions. After the test was completed the fabric wheel was removed from the apparatus and the loose simulant was removed from the fabric using a HEPA filtered vacuum cleaner with a soft brush.

\section{Characterization Protocols}

Samples of the fabric $15 \times 17 \mathrm{~mm}$ were cut out of the abraded region and mounted in a sample handler that was designed to fit within the Field Emission Scanning Electron Microscope (FESEM) used to characterize the samples. This enabled the samples to be stored and handled in a safe way that prevented additional damage which could confound the results.

The samples were first imaged under a Leica MZ16 optical microscope fitted with digital image capture. A full image of the fabric sample was first obtained centered in the middle of the fabric sample. Five regions including the center and positions 3 $\mathrm{mm}$ north, south, east, and west of the center were imaged at $10 x$, $25 \times, 50 \times$, and $100 \times$ magnification.

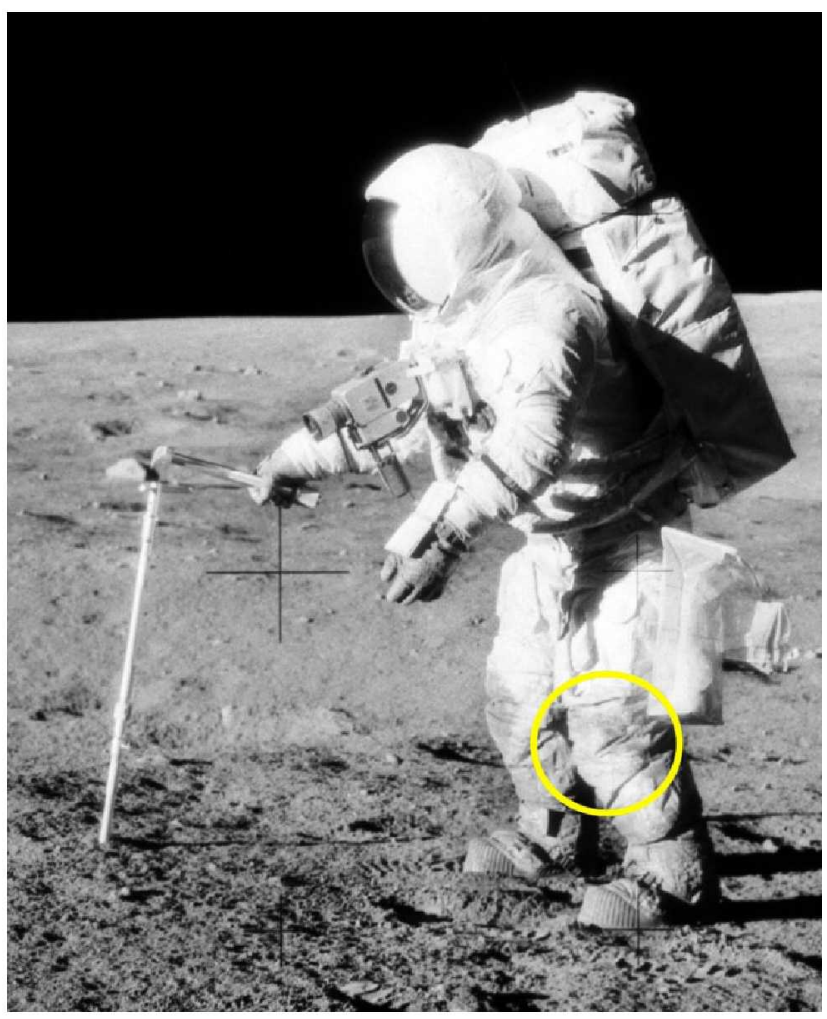

Figure 3.-NASA Photograph AS12-49-7286A, Apollo 12 astronaut Alan Bean on the lunar surface. The sample used in this study was taken from the left knee area which can be seen to be among the dustiest portions of the suit.

The samples were first imaged under a Leica MZ16 optical microscope fitted with digital image capture. A full image of the fabric sample was first obtained centered in the middle of the fabric sample. Five regions including the center and positions $3 \mathrm{~mm}$ north, south, east, and west of the center were imaged at $10 \times, 25 \times, 50 \times$, and $100 \times$ magnification.

The samples were then scanned with a Hitachi Model S-4700 FESEM using acceleration voltages ranging from 1 to $6 \mathrm{kV}$. This enabled the samples to be imaged without the addition of conducting coatings. The same five regions that were imaged with the optical microscope were scanned at $50 \times, 100 \times, 250 \times, 1000 \times$, and $4500 \times$ magnification.

\section{Results and Discussion}

A small sample of the outer layer of the suit worn by Alan Bean during Apollo 12 cut from the area of the left knee was used as the baseline material. As can be seen in Figure 3, it was among the dirtiest portions of the suit. Microscopic examination revealed that a fair amount of particulate was present in the fabric, but it was not easily removed. An indepth study of this and other Apollo suits has recently been completed (Ref. 7). 
The abrasive damage that was observed on that fabric sample was taken to be typical of what could be expected on the Moon. Thus, the pressure exerted by the abrasion wheels was varied until it could reproduce the damage structures observed in the Apollo fabric. Then the candidate fabrics were tested under the same conditions to get a measure of the comparative damage that could be expected with each fabric type after a comparable period of wear on the lunar surface.

\section{Alan Bean FEP Twill Weave Suit Material}

Photomicrographs of the FEP fabric from Alan Bean's suit are shown in Figure 4. There is little plastic deformation of the fibers, but shredding of many of the filaments, particularly in the top layer is apparent. The protocol was modified to produce abrasive damage of this morphology in candidate fabrics to evaluate their abrasion resistance to lunar regolith.
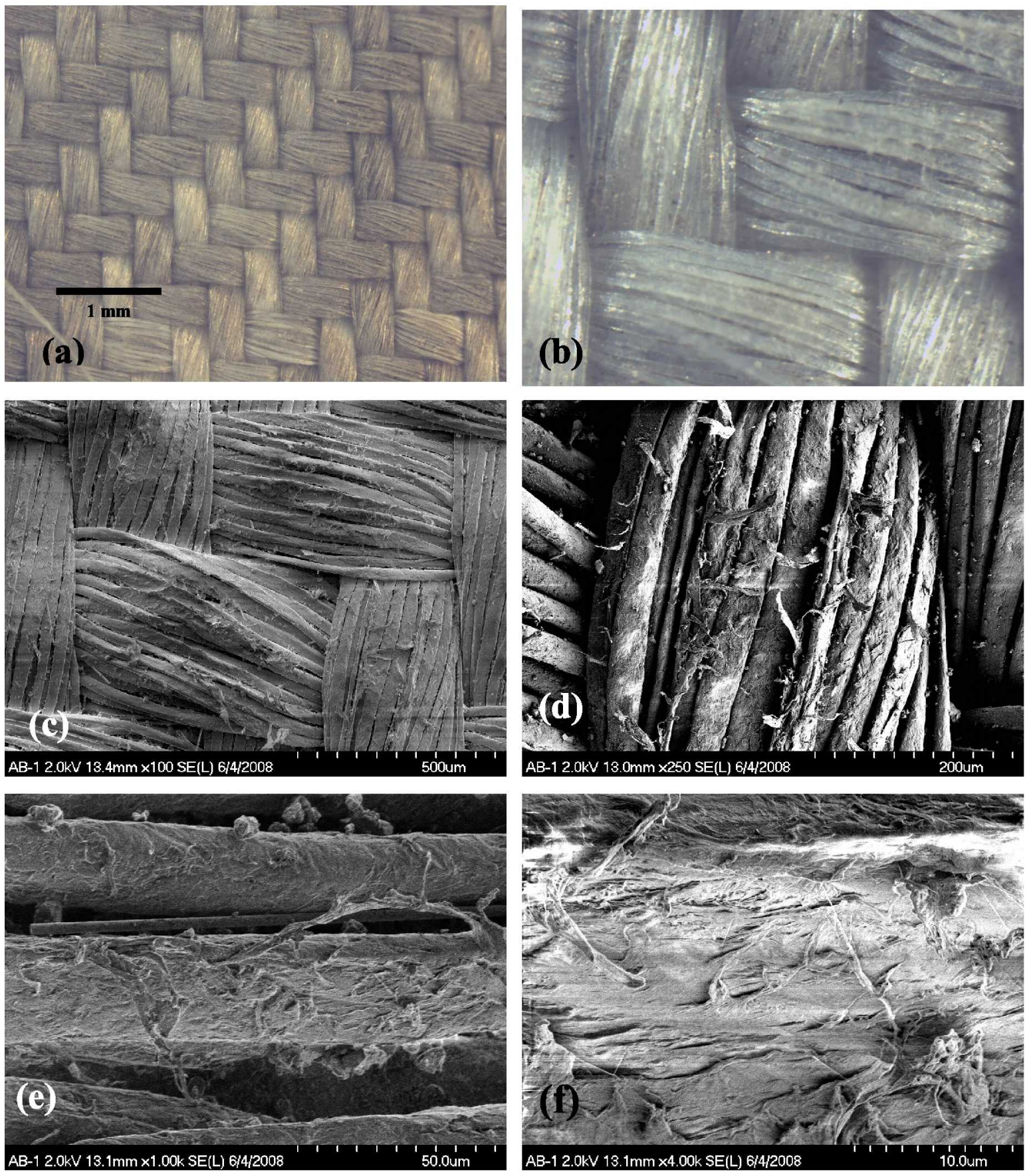

Figure 4.-Optical (a) and (b), and FESEM (c) to (f) photomicrographs of fabric from the left knee of Apollo 12 astronaut Alan Bean's suit. 


\section{FEP Twill Weave Abraded Using the PTFE Wheel}

Figure 5 shows the results of dust abrasion using the PTFE wheel of the same FEP material, from the same era, as was used in the Alan Bean suit. It can be seen that there was extensive plastic deformation of the surface of the filaments. Unlike the Apollo sample, the surfaces were smeared out to such an extent that individual filaments within the tows cannot be distinguished.
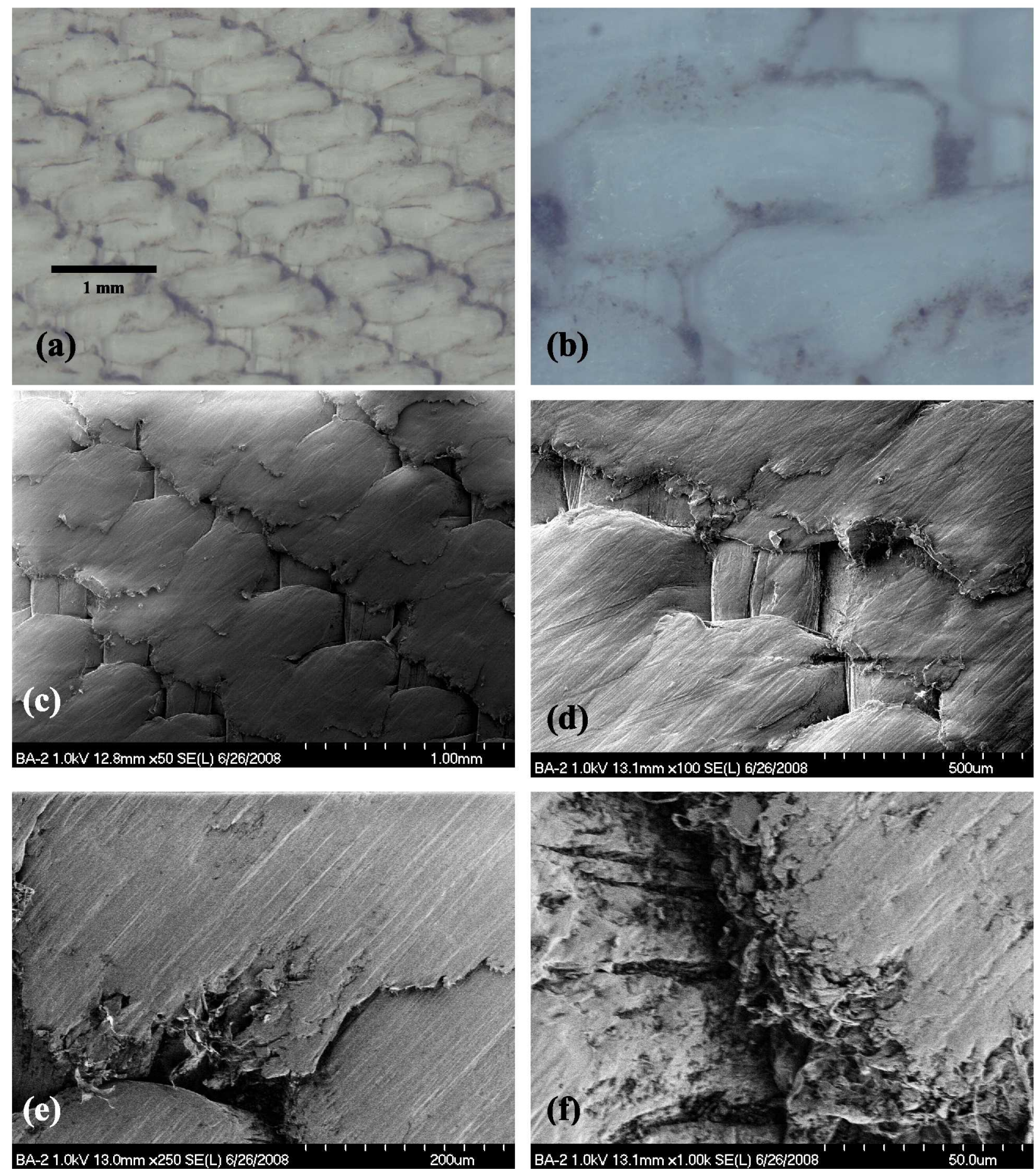

Figure 5.-Optical (a) and (b), and FESEM (c) to (f) photomicrographs of Apollo era woven FEP fabric abraded for 8000 cycles with activated lunar simulant in a lunar simulation chamber using the PTFE wheel. 


\section{Orthofabric Abraded Using the PTFE Wheel}

The series of photomicrographs shown in Figure 6 are the result using the same orthofabric material used in the state of the art pressure garments used on the Space Shuttle and the
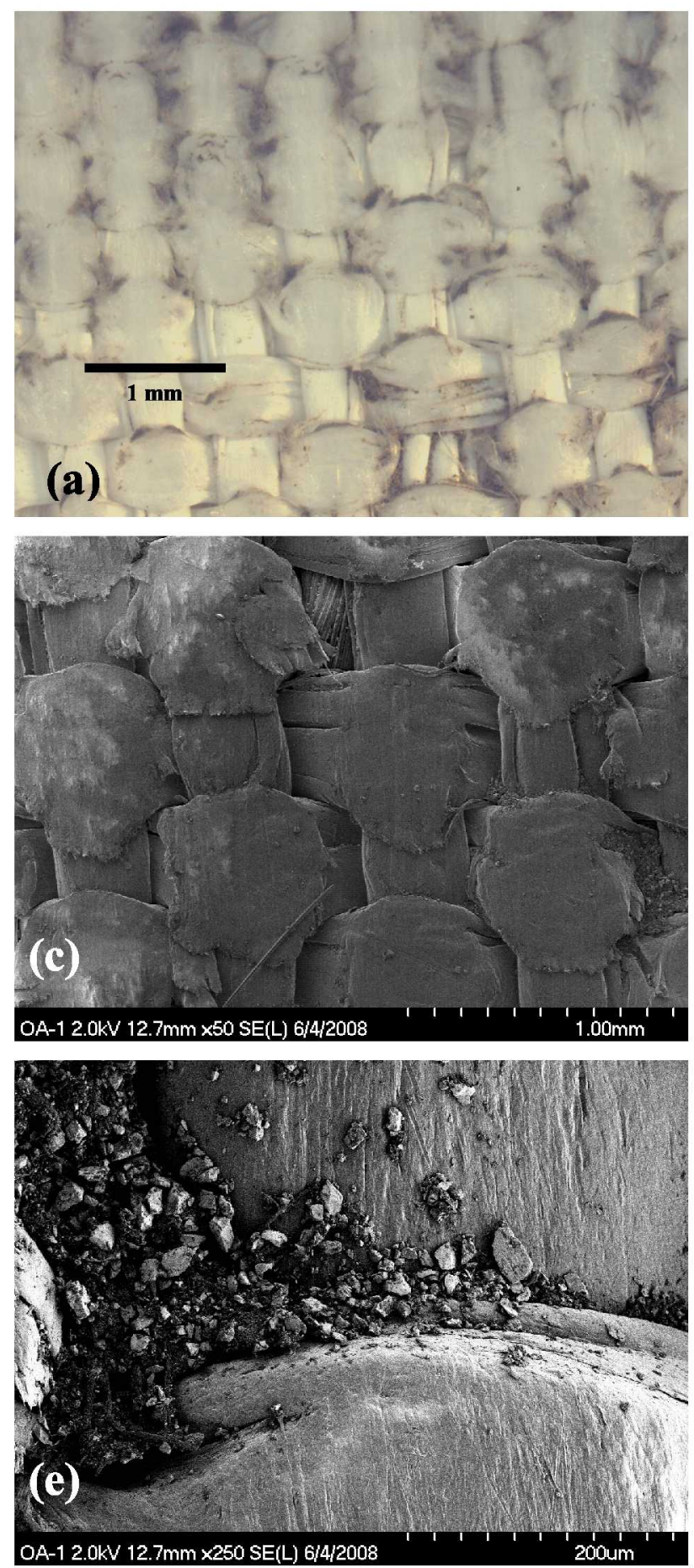

International Space Station abraded using the PTFE wheel. It can be seen that there is extensive plastic deformation of the surface of the filaments. The surfaces are smeared out to such an extent that individual filaments within the tows cannot be distinguished.
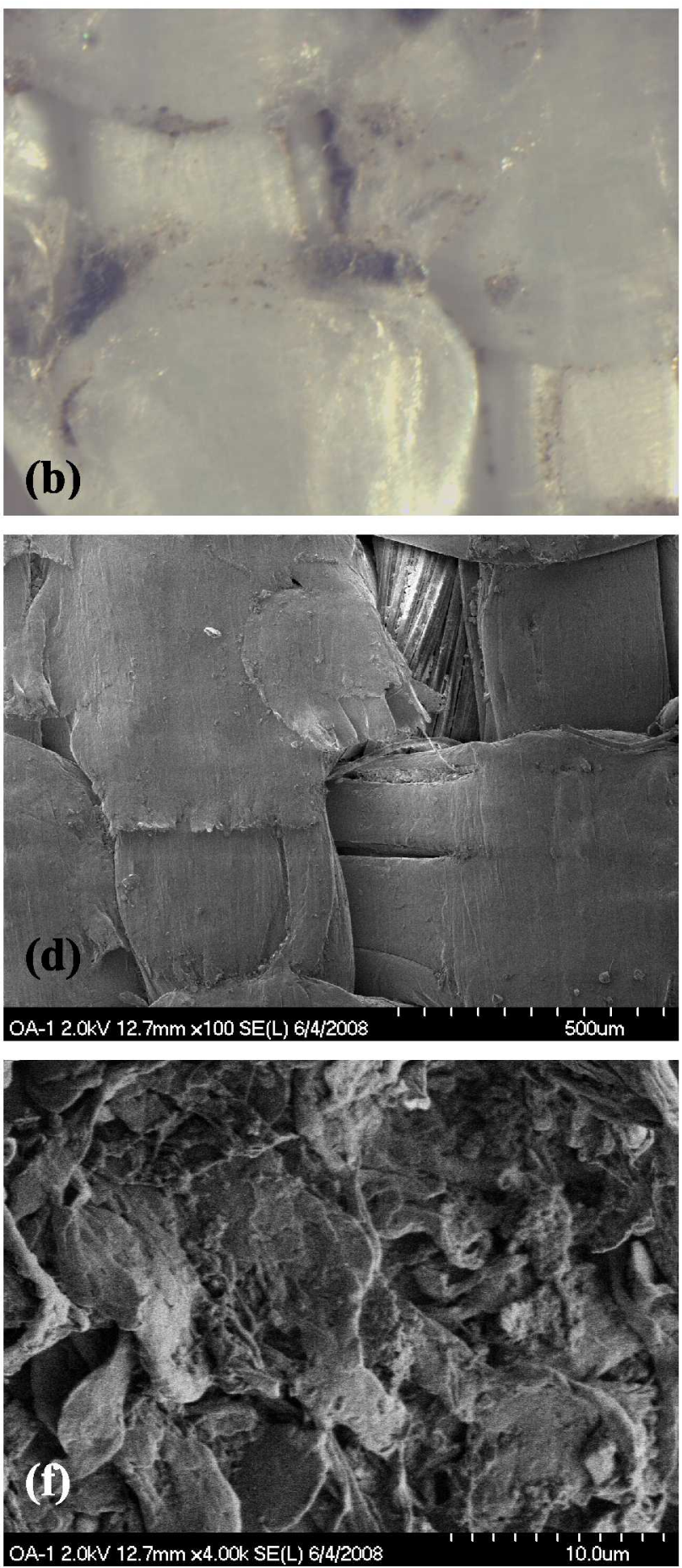

Figure 6.-Optical (a) and (b), and FESEM (c) to (f) photomicrographs of Orthofabric abraded using the PTFE wheel for 8000 cycles with activated lunar simulant in a lunar simulation chamber. 


\section{Tyvek Abraded Using the PTFE Wheel}

The Tyvek sustained little damage when abraded using the PTFE wheel. As shown in Figure 7, the filaments seem to be unaffected even at the highest magnifications. This may be due, in part, to the smoother texture of the Tyvek, not being a woven material. It is worth noting that the Tyvek also did not allow penetration by the dust. This is significant in that dust passes right though uncoated woven fabrics, making the layer immediately below this vulnerable to the same abrasion over extended use. It has been reported that when the Bean suit was disassembled at White Sands in 1970, there was as much lunar dust on the bottom (unexposed side) of the cover layer as the top (Ref. 8).
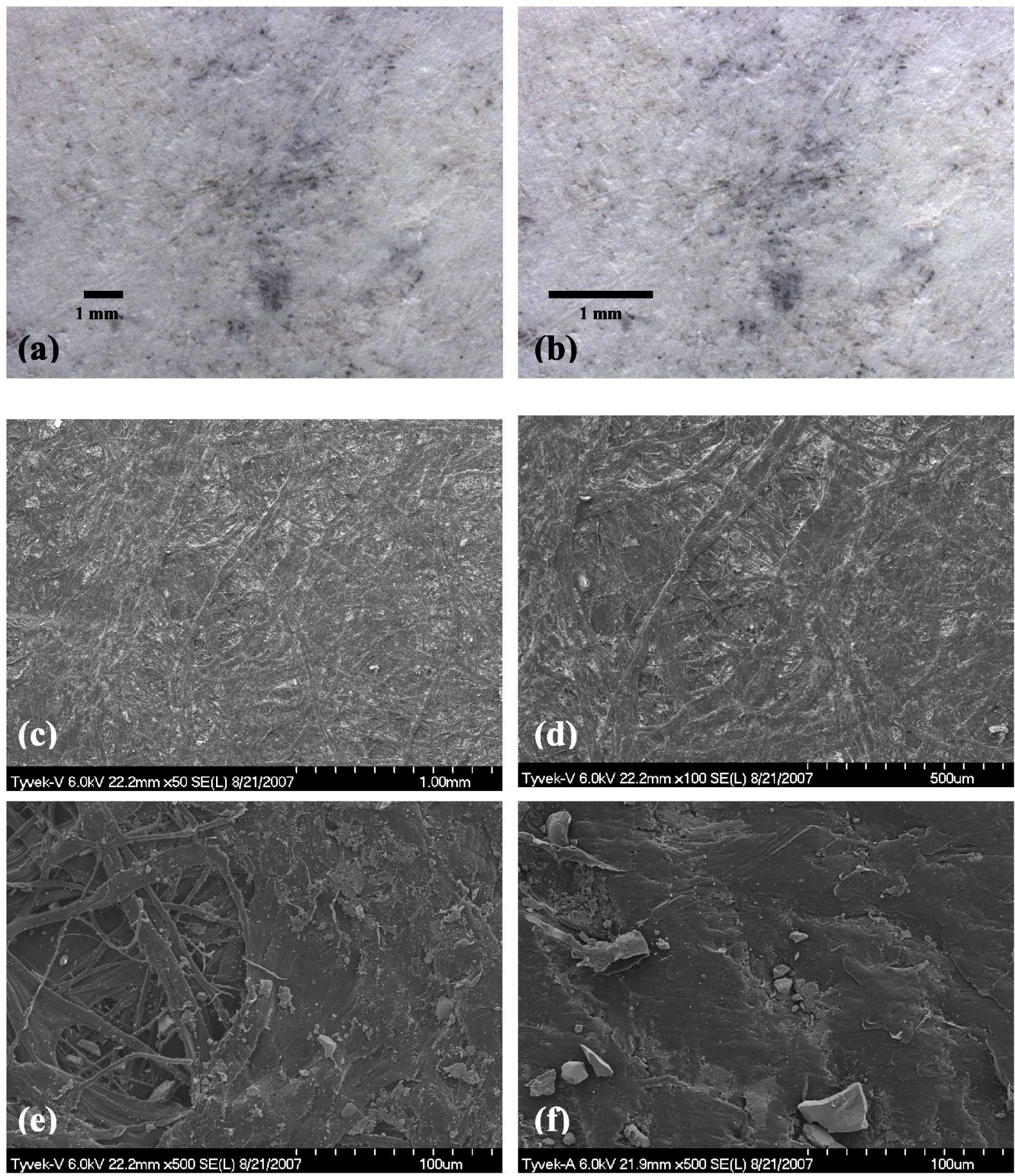

Figure 7.-Optical (a) and (b), and FESEM (c) to (f) photomicrographs of Tyvek abraded using the PTFE wheel for $\mathbf{8 0 0 0}$ cycles with activated lunar simulant in a lunar simulation chamber. 


\section{Kevlar With Calendered Silicone Coating Abraded Using Low Pressure and S-39 Wheel}

As summarized in Figure 8, at low magnification the surface of the silicone-coated Kevlar shows little plastic deformation after abrasion with JSC-1a using the S-39 wheel, indicating that the applied pressure was not too great. At 50x (Fig. 8(c)), virtually all of the filaments in the top layer of the horizontal running tow are seen to be broken. At higher magnification (Fig. 8(d)) it can be seen that the fibers were plastically deformed before they broke. Individual filaments have been flattened and splayed out to where they resemble kelp beds found in the ocean (Fig. 8(e)). A large amount of dust particle debris was worked into the fabric structure, and this appears to have damaged fibers in lower layers. However, virtually no dust penetrated through the fabric through the calendered silicone coating.
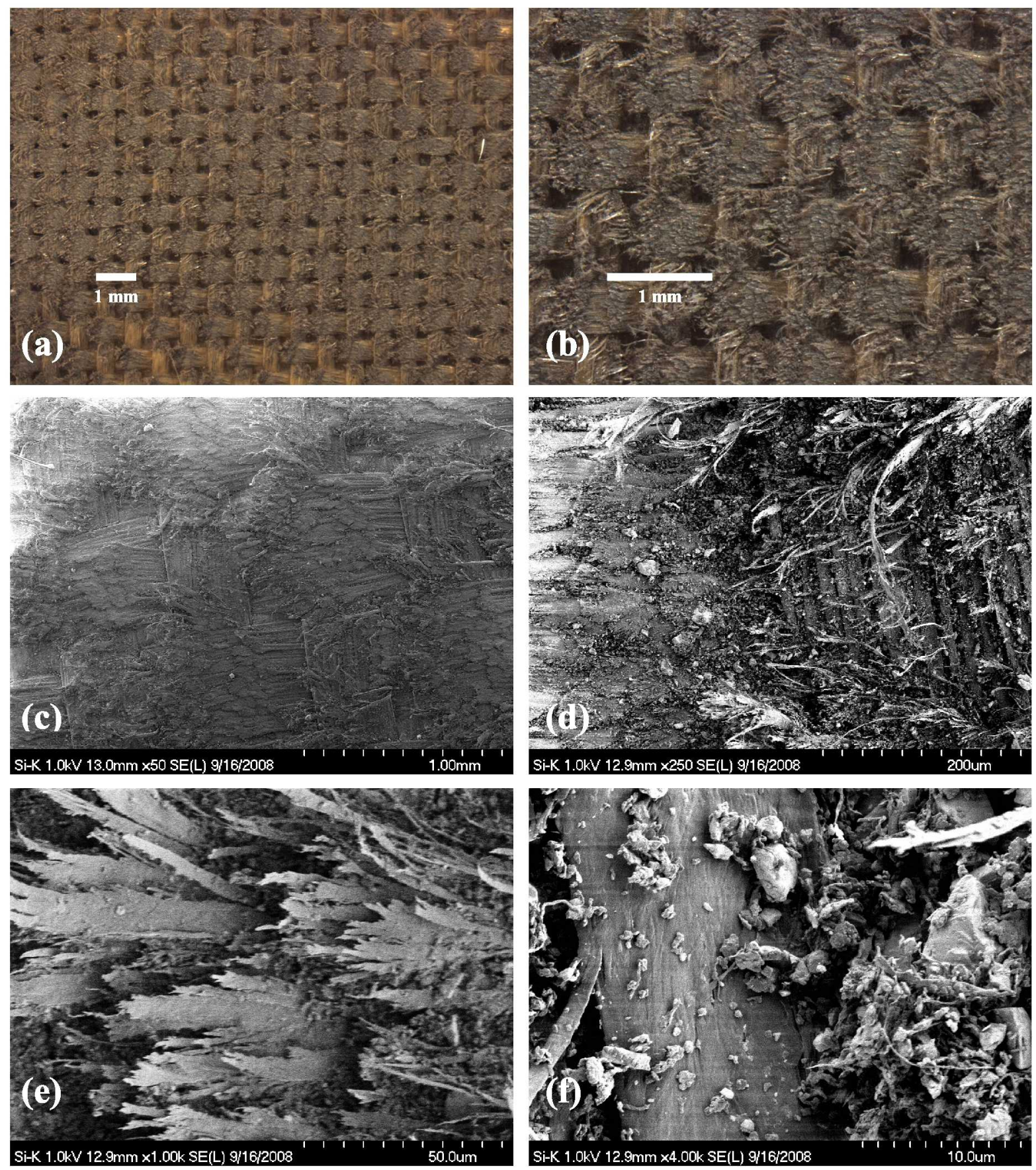

Figure 8.-Optical (a) and (b), and FESEM (c) to (f) photomicrographs of Kevlar abraded for 8000 cycles with JSC1a lunar simulant using S-39 wheels under low pressure and ambient conditions. 


\section{Silicone-Coated Vectran Abraded Using Low Pressure and S-39 Wheel}

It is illustrated in Figure 9 that the top layer of Vectran filaments were abraded through, much like the Kevlar when they were abraded with JSC-1a simulant using S-39 abrasion wheels. There seems to be less plastic deformation with the Vectran, with
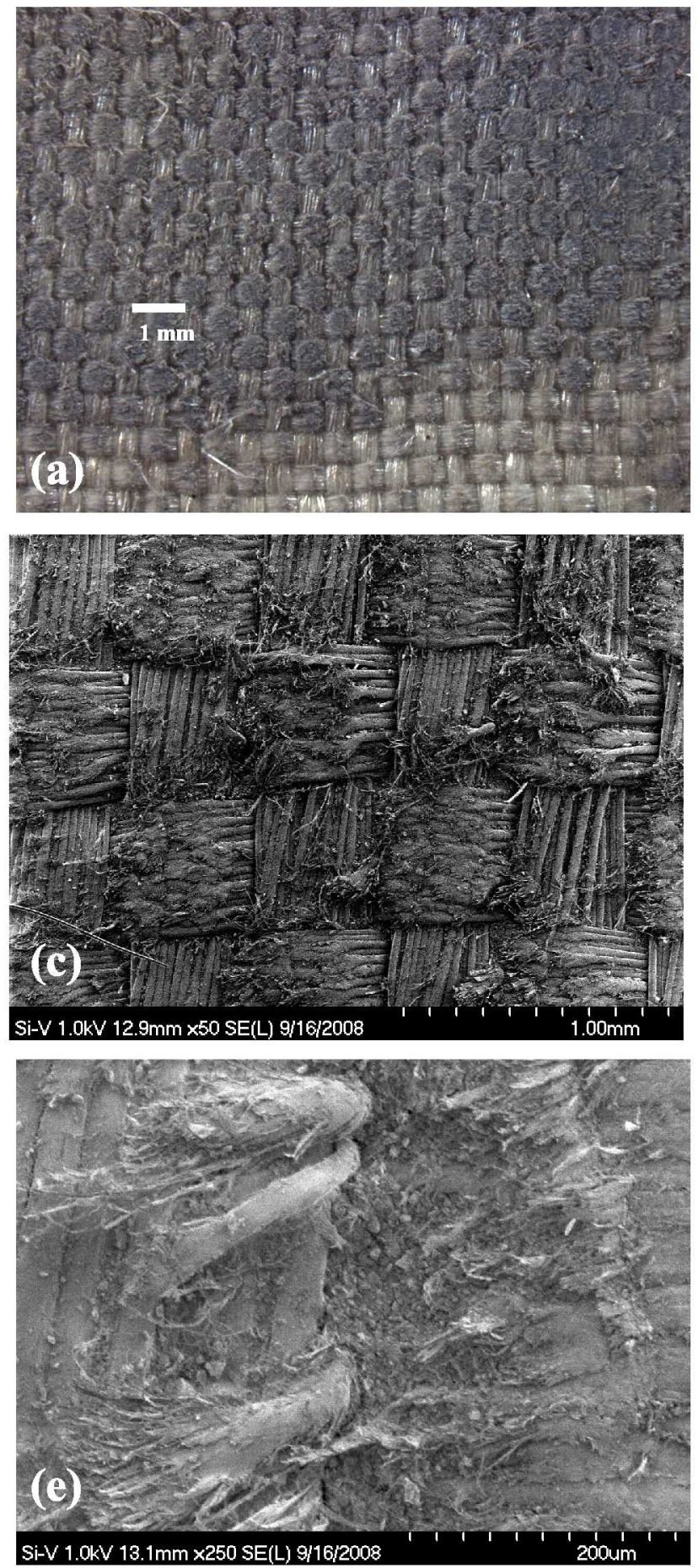

the fibers wearing through and in some cases the fiber ends being folded over the adjacent tow. High magnification (Figs. 9(e) and (f)) shows that the filaments were shredded, but the extreme plastic deformation seen with the Kevlar is not seen here. Some of the dust particles penetrated completely through the Vectran fabric.
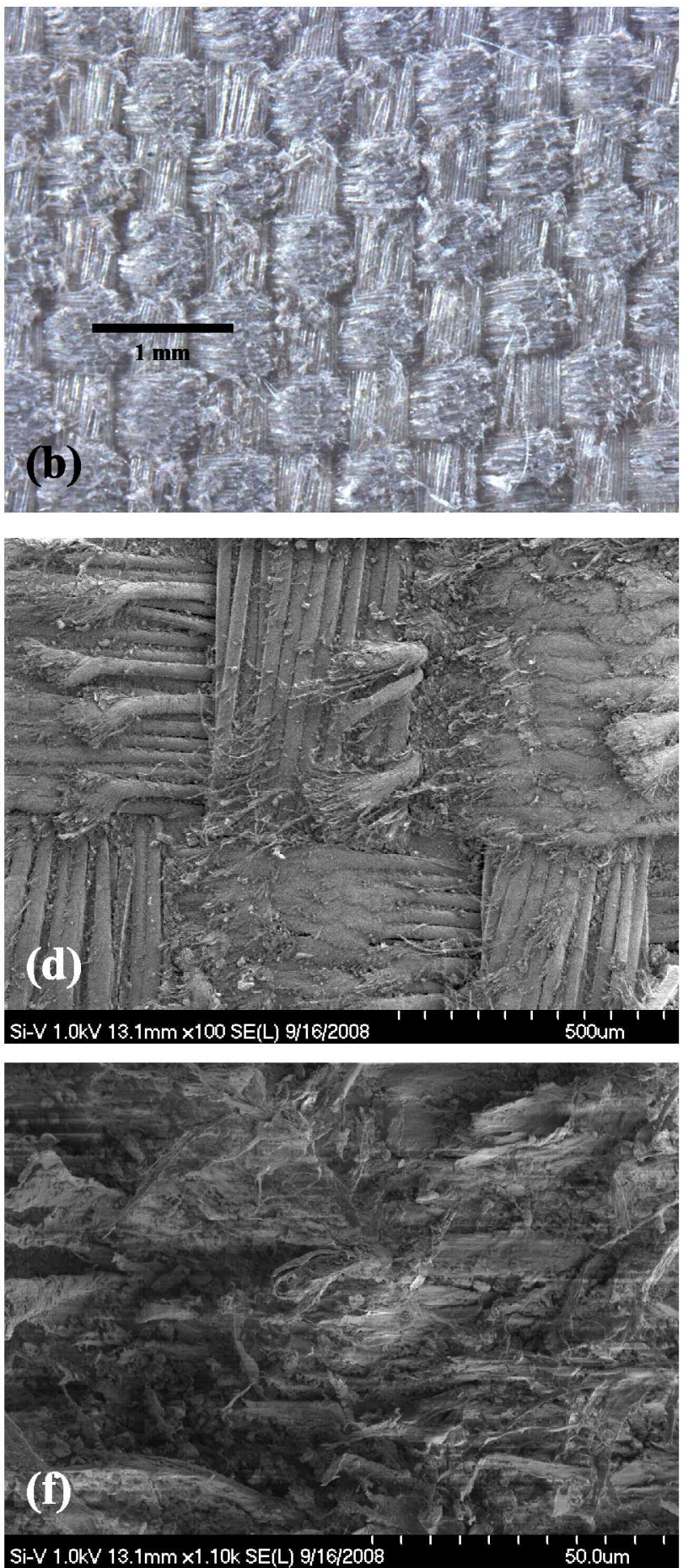

Figure 9. - Optical (a) and (b), and FESEM (c) to ( $f$ ) photomicrographs of Vectran abraded for 8000 cycles with JSC1a lunar simulant using S-39 wheels under low pressure and ambient conditions. 


\section{Silicone-Coated Orthofabric Abraded With Low Pressure and S-39 Wheel}

Figure 10 illustrates that although there were some areas in the Orthofabric where the filament surfaces were smeared together by excessive pressure when they were abraded with JSC-1a simulant using S-39 abrasion wheels, for the most part tows were not worn through. Most of the filament damage started with plastic deformation and appeared to proceed through a stretching and breaking mechanism. The silicone coating kept virtually all of the dust from penetrating the fabric.
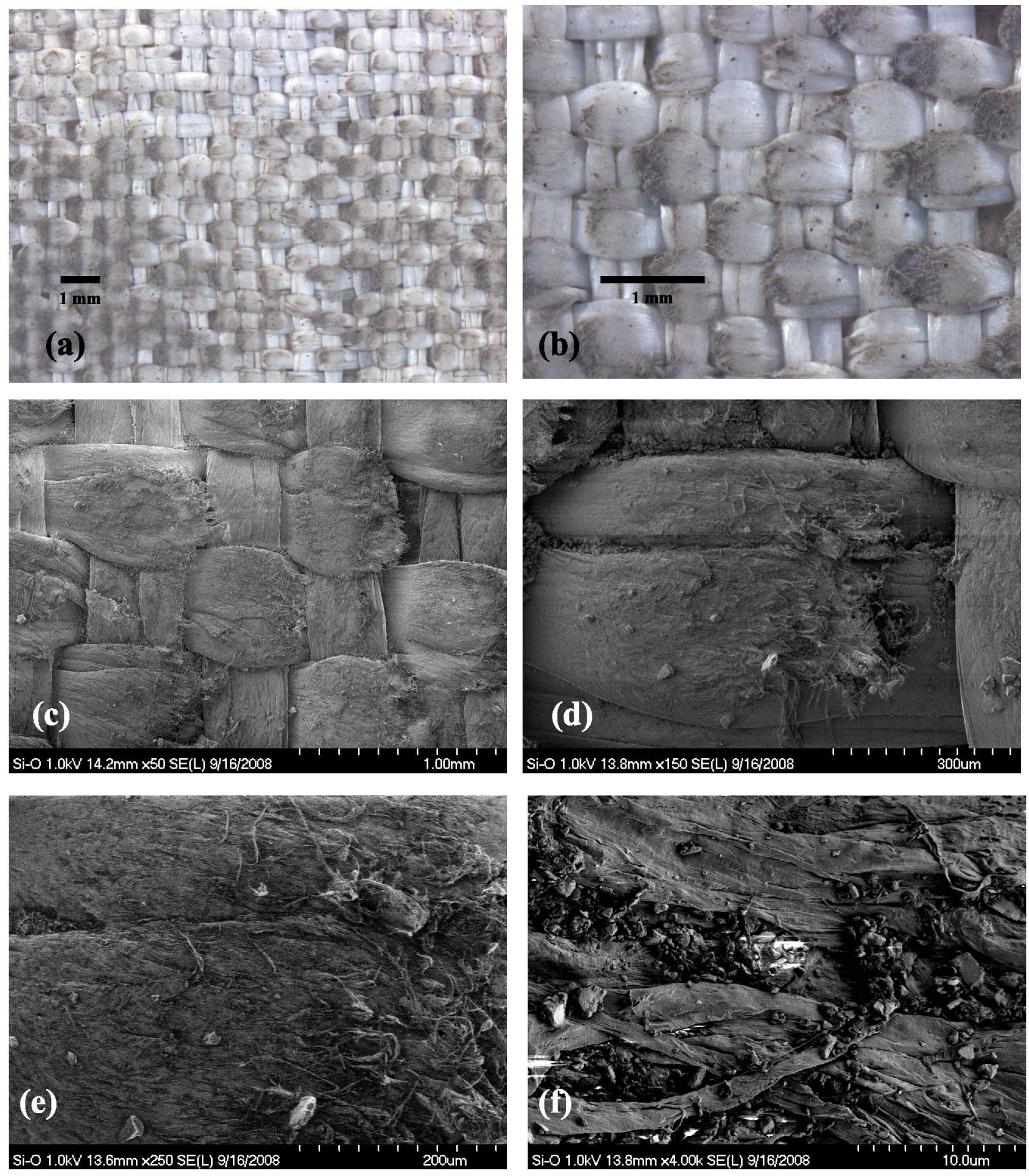

Figure 10.-Optical (a) and (b), and FESEM (c) to (f) photomicrographs of Orthofabric abraded for 8000 cycles with JSC-1a lunar simulant using S-39 wheels under low pressure and ambient conditions. 


\section{Tyvek Abraded With Low Pressure and S-39 Wheel}

Figure 11 summarizes the Tyvek results when they were abraded with JSC-1a simulant using S-39 abrasion wheels. As in the previous tests, the Tyvek sustained the least abrasive damage. Again no damage to the filaments is seen even at the highest magnifications. As before, the Tyvek did not allow any penetration of the dust.
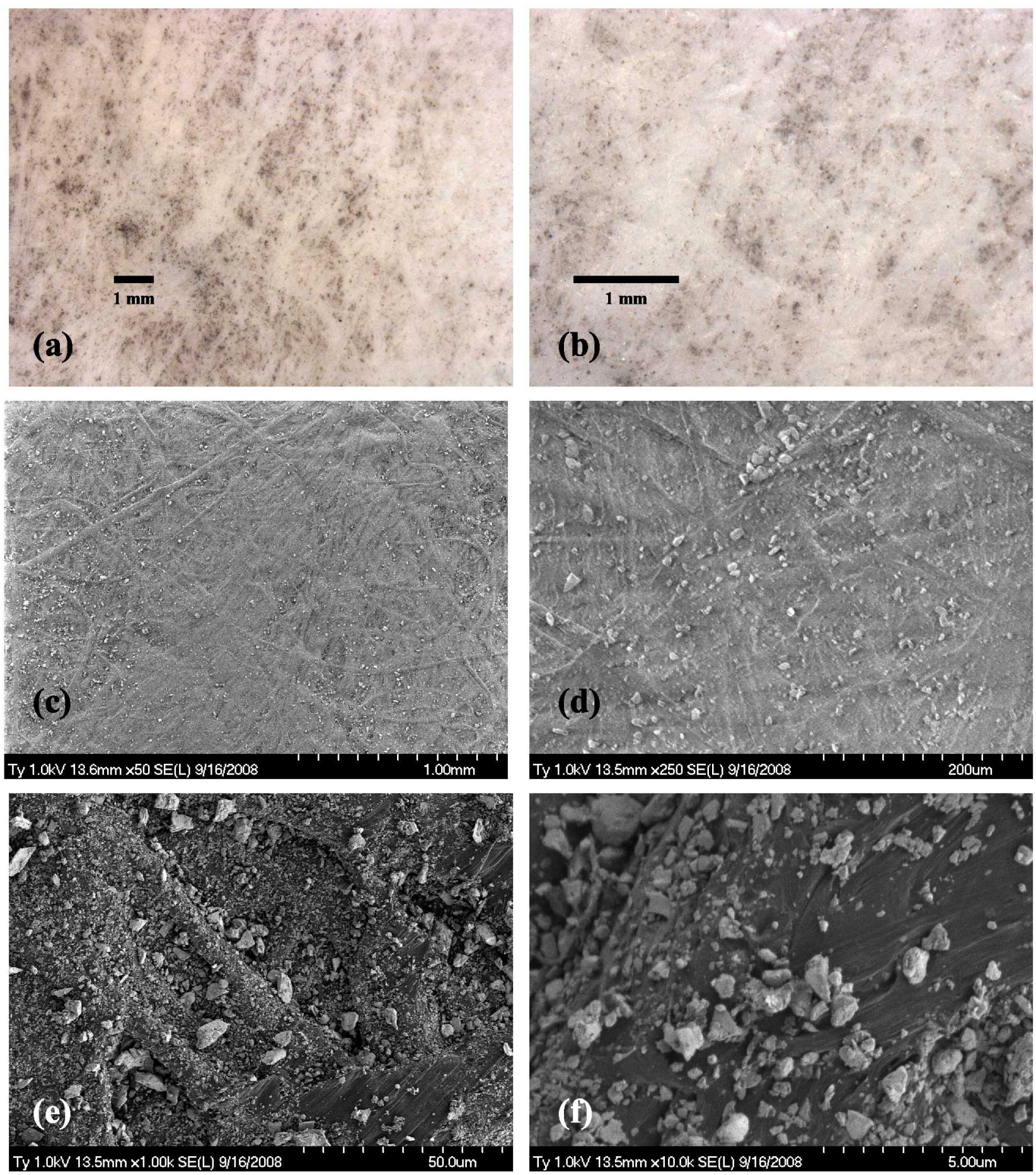

Figure 11.-Optical (a) and (b), and FESEM (c) to (f) photomicrographs of Tyvek abraded for 8000 cycles with JSC1a lunar simulant using S-39 wheels under low pressure and ambient conditions. 


\section{Conclusions}

A protocol has been developed that mimics the type of lunar soil abrasion damage seen on Apollo spacesuits. Loose JSC1A lunar simulant was applied to the fabric which was lightly loaded and subjected to the "Rotary Platform, Double Head Method" of fabric abrasion, utilizing leather coated abrasion wheels. Lunar simulant was ground into the fabrics at $70 \mathrm{rpm}$ for 800 cycles. This protocol was then applied to four materials (Kevlar, Vectran, Orthofabric, and Tyvek) that are candidates for advanced spacesuits. Three of the four new candidate fabrics (all but Vectran) were effective at keeping the dust from penetrating to layers beneath. In the cases of Kevlar and Orthofabric this was accomplished by the addition of a silicone layer. In the case of Tyvek, the paper structure was dense enough to block dust transport. The least abrasive damage was suffered by the Tyvek. This was thought to be due in large part to its non-woven paper structure. The woven structures were all abraded where the top of the weave was struck by the abrasive. Of these, the Orthofabric suffered the least wear, with both Vectran and Kevlar suffering considerably more extensive filament breakage.

\section{References}

1. MSC01855 Apollo 12 Mission Report (March 1970) pp. 9-21.

2. Conrad, Pete, Apollo 12 Technical Crew Debriefing (December 1, 1969) pp. 10-54.

3. Private communications, J.J. Kosma, NASA Johnson Space Center (2007).

4. Gaier, J.R., and Sechkar, E.A., "Lunar Simulation in the Lunar Dust Adhesion Bell Jar," NASA/TM-2007-214704.

5. ibid.

6. D.S. McKay, et al., "A New Lunar Regolith Simulant," Lunar and Planetary Science XXIV, Lunar and Planetary Society Institute, Houston, TX, 1993.

7. U.D. Smith, Interim Report: Examination of Material and Items Removed from Space Suit S/N067, TR-168-001 (1970).

8. Christoffersen, R., Noble, S., Kosmo, J.J., Young, A., Meador, M.A.B., "Lunar Dust Effects on Spacesuit Systems: Insights from the Apollo Spacesuits," NASA TP21476 (2009). 


\begin{tabular}{|c|c|c|}
\hline \multicolumn{2}{|c|}{ REPORT DOCUMENTATION PAGE } & $\begin{array}{l}\text { Form Approved } \\
\text { OMB No. 0704-0188 }\end{array}$ \\
\hline \multicolumn{3}{|c|}{ 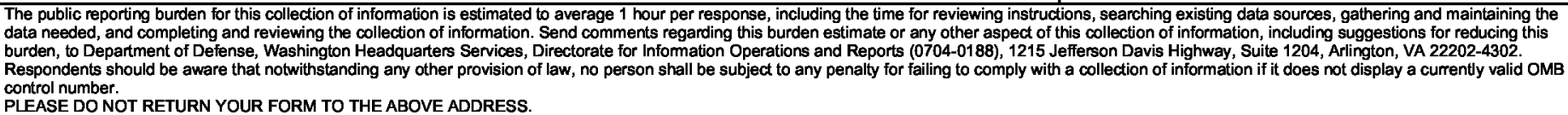 } \\
\hline $\begin{array}{l}\text { 1. REPORT DATE (DD-MM-YYYY) } \\
01-10-2009\end{array}$ & $\begin{array}{l}\text { 2. REPORT TYPE } \\
\text { Technical Memorandum }\end{array}$ & 3. DATES COVERED (From - To) \\
\hline \multirow{3}{*}{\multicolumn{2}{|c|}{$\begin{array}{l}\text { 4. TITLE AND SUBTITLE } \\
\text { Abrasion of Candidate Spacesuit Fabrics by Simulated Lunar Dust }\end{array}$}} & 5a. CONTRACT NUMBER \\
\hline & & 5b. GRANT NUMBER \\
\hline & & 5c. PROGRAM ELEMENT NUMBER \\
\hline \multirow{3}{*}{\multicolumn{2}{|c|}{$\begin{array}{l}\text { 6. AUTHOR(S) } \\
\text { Gaier, James, R.; Meador, Mary, Ann; Rogers, Kerry, J.; Sheehy, Brennan, H. }\end{array}$}} & 5d. PROJECT NUMBER \\
\hline & & 5e. TASK NUMBER \\
\hline & & $\begin{array}{l}\text { 5f. WORK UNIT NUMBER } \\
\text { WBS 936374.04.08.03 }\end{array}$ \\
\hline \multicolumn{2}{|c|}{$\begin{array}{l}\text { 7. PERFORMING ORGANIZATION NAME(S) AND ADDRESS(ES) } \\
\text { National Aeronautics and Space Administration } \\
\text { John H. Glenn Research Center at Lewis Field } \\
\text { Cleveland, Ohio 44135-3191 }\end{array}$} & $\begin{array}{l}\text { 8. PERFORMING ORGANIZATION } \\
\text { REPORT NUMBER } \\
\text { E-16958-1 }\end{array}$ \\
\hline \multirow{2}{*}{\multicolumn{2}{|c|}{$\begin{array}{l}\text { 9. SPONSORING/MONITORING AGENCY NAME(S) AND ADDRESS(ES) } \\
\text { National Aeronautics and Space Administration } \\
\text { Washington, DC 20546-0001 }\end{array}$}} & $\begin{array}{l}\text { 10. SPONSORING/MONITOR'S } \\
\text { ACRONYM(S) } \\
\text { NASA }\end{array}$ \\
\hline & & $\begin{array}{l}\text { 11. SPONSORING/MONITORING } \\
\text { REPORT NUMBER } \\
\text { NASA/TM-2009-215800 }\end{array}$ \\
\hline \multicolumn{3}{|c|}{$\begin{array}{l}\text { 12. DISTRIBUTION/AVAILABILITY STATEMENT } \\
\text { Unclassified-Unlimited } \\
\text { Subject Category: } 91 \\
\text { Available electronically at http://gltrs.grc.nasa.gov } \\
\text { This publication is available from the NASA Center for AeroSpace Information, 443-757-5802 }\end{array}$} \\
\hline
\end{tabular}

\section{SUPPLEMENTARY NOTES}

\section{ABSTRACT}

A protocol has been developed that produced the type of lunar soil abrasion damage observed on Apollo spacesuits. This protocol was then applied to four materials (Kevlar (DuPont), Vectran (Kuraray Co., Ltd.), Orthofabric, and Tyvek (DuPont)) that are candidates for advanced spacesuits. Three of the four new candidate fabrics (all but Vectran) were effective at keeping the dust from penetrating to layers beneath. In the cases of Kevlar and Orthofabric this was accomplished by the addition of a silicone layer. In the case of Tyvek, the paper structure was dense enough to block dust transport. The least abrasive damage was suffered by the Tyvek. This was thought to be due in large part to its non-woven paper structure. The woven structures were all abraded where the top of the weave was struck by the abrasive. Of these, the Orthofabric suffered the least wear, with both Vectran and Kevlar suffering considerably more extensive filament breakage.

15. SUBJECT TERMS

Lunar soil; Lunar dust; Abrasion; Extravehicular activity; Fabrics

\begin{tabular}{|c|c|c|c|c|c|}
\hline \multicolumn{3}{|c|}{ 16. SECURITY CLASSIFICATION OF: } & \multirow{2}{*}{$\begin{array}{l}\text { 17. LIMITATION OF } \\
\text { ABSTRACT } \\
\text { UU }\end{array}$} & \multirow{2}{*}{$\begin{array}{l}\text { 18. NUMBER } \\
\text { OF } \\
\text { PAGES } \\
18\end{array}$} & \multirow{2}{*}{$\begin{array}{l}\text { 19a. NAME OF RESPONSIBLE PERSON } \\
\text { STI Help Desk (email:help@sti.nasa.gov) } \\
\text { 19b. TELEPHONE NUMBER (include area code) } \\
\text { 443-757-5802 }\end{array}$} \\
\hline $\begin{array}{l}\text { a. REPORT } \\
U\end{array}$ & $\begin{array}{l}\text { b. ABSTRACT } \\
U\end{array}$ & $\begin{array}{l}\text { c. THIS } \\
\text { PAGE } \\
\text { U }\end{array}$ & & & \\
\hline
\end{tabular}



